\title{
Effect of different parameters of shock on tonic immobility
}

\author{
RICHARD F. NASH \\ Marquette University, Milwaukee, Wisconsin 53239
}

and

GORDON G. GALLUP, JR.

Tulane University, New Orleans, Louisiana 70118

\begin{abstract}
Four separate experiments were conducted with chickens to explore the effects of various parameters of electric shock on tonic immobility. Immobilizing subjects at varying times after the receipt of shock affected the duration of immobility only after delays of over 15 min. Duration of shock affected immobility differently, depending upon whether alternating current or continuous direct current was used. The effects of continuous dc, pulsating dc, and ac shock were also examined. The results were discussed in terms of shock onset-offset characteristics being an important consideration.
\end{abstract}

Tonic immobility is represented by a state of profound catatonic-like unresponsiveness which follows briet exposure to physical restraint. Although the exact mechanisms underlying tonic immobility remain obscure, the duration of the reaction has proven directionally sensitive to manipulations designed to affect fear (Gallup, 1974). Exposure to aversive events prior to induction reliably increases duration of immobility, while handling, taming, and tranquilizer ingestion result in diminished reactions.

A brief shock given a few seconds before the onset of tonic immobility has been shown to prolong the reaction in chickens (Gallup, Creekmore. \& Hill, 1970). and the stronger the shock the longer the immobility response (Gallup, 1973; Gallup, Nash, Potter. \& Donegan. 1970). Shock applied via leads tied to the subject's legs seems more effective than grid shock (Maser, Gallup. \& Barnhill, 1973), and exposure to inescapable shock has a more potent long-term effect on tonic immobility than escapable shock (Maser \& Gallup, 1974).

The robust effects of shock on tonic immobility raise several questions with methodological and theoretical implications. For example, how long do the effects of a single shock last? Does the duration of shock make a difference? And, finally. do alternating and direct-current shock sources produce equivalent effects? The present study attempts to examine these issues as they relate to immobility in chickens.

Parts of this reseatch were supported by Grant 5061 from the Committee on Research at Marquette University to R. F. Nash. The atuthors gratefully atknowledge the assistance of J. Frank Popplewell and Martin J. Schade in data collection. Requests for reprints should be sen to Richard F. Nash. Department of Psichology. Marcutette Lniversits. Milwatukce. Wisconsin 5.3233.

\section{EXPERIMENT I}

The first study was designed to determine how long the effects of shock last. The time between receipt of shock and onset of tonic immobility was studied.

\section{Method}

The subjects were 70 Production Red chicks (Gallus gallus), obtained from a Mississippi hatchery at 1 day of age. The chicks were housed in commercial brooders and given continuous access to Purina Chick (how (Growena) and water. The photoperiod in effect during rearing was $14 \mathrm{~h}$ of artificial light per day.

A Foringer constant-current dc shock generator (Model 1154-MIII) was used; duration of shock was controlled with a Hunter decade interval timer (Model 11-C). Time between receipt of shock and onset of immobility was monitored by a stopwatch, as was the duration of the ensuing immobility response. Animals were tested in a three-sided $(.61 \times .61 \times .50 \mathrm{~m})$ wooden induction box mounted on at table. This arrangement eliminated extraneous visual cuess.

At 21 daws of age. all chicks were given 4 days of habituation training. Habiuation consisted of manually testraining a bird on its right side for $15 \mathrm{sec}$ in the induction box. The duration of each immobility episnde was terminated after about $30 \mathrm{sec}$ by gentle prodding. Each hird was given tive ind uctions per day. with a 60 -sec intertrial interval. During each period of immobility, the experinenter sall quietly on a chair about $.9 \mathrm{~m}$ away and avoided making direct eve contact with the subject. Large plywood boxes. provided with ventilation holes and food. were used to transport the subjects and at pre-and posttest holding boxes located outside the testing roont.

On the day after the last habituation trial, subjects were tested. Order of experimental treatments were determined from a table of random pernutations. Inmediately prior to testing, the chick's feet and legs were dipped into a mild saline solution; a bare wire leading from one of the two terminals on the shock generator. via the interval timer. was wrapped around each leg. While being gently held by the experimenter. the subject then received a 2 -sec, 3.5-mA dc shock. Following shock termination and lead removal, the bird was restrained immediately or at $2.5,5,10,15,60$, or $240 \mathrm{~min}$ after the receipt of shock. The animal was held on its right side for 


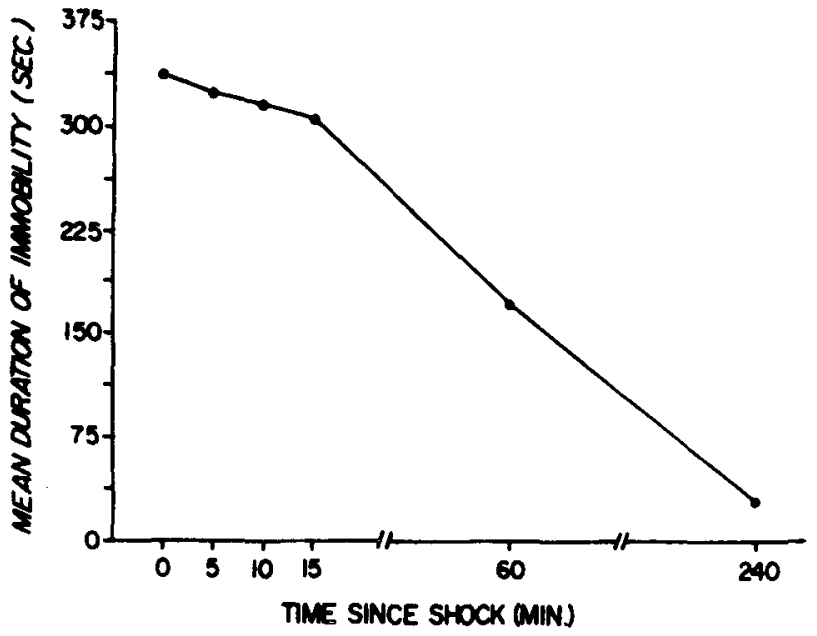

Figure 1. Duration of immobility as a function of the time delay between shock offset and immobility onset.

$15 \mathrm{sec}$. Duration of immobility was measured from the time manual restraint ended until the bird rose to its feet. If a chick did not show immobility after the first induction, it was given successive 15-sec inductions, using a 15-sec intertrial interval, until immobility was obtained or until five inductions had been administered, in which case a duration of zero was recorded.

\section{Results}

Figure 1 shows that the effects of a single shock last for a considerable period of time and only begin to diminish after about $15 \mathrm{~min}$. For purposes of analysis, the duration of immobility data in seconds were normalized, using a $\log _{10}$ transformation. A one-way analysis of variance, computed on the transformed data, revealed a significant effect of time since receipt of shock, $F(6.63)=4.80, p<.001$. A Duncan's multiple range test showed that subjects in the $240-$ min delay group remained immobile for significantly $(p<.05)$ shorter periods of time than those in the $0-, 2.5-, 5-, 10-, 15-$, and $60-\mathrm{min}$ delay groups. None of the other group comparisons were significant.

The effect of time since shock on the number of inductions needed to elicit immobility is presented in Table 1. Analysis of variance on the induction data was signiticant. $F(6,63)=6.72, p<.001$. A Duncan's multiple range test revealed that the required number of inductions was greater $(\mathrm{p}<.05)$ for the 240-min delay condition than for all other groups. The 60-min delay condition required significantly more inductions than the 0-, 2.5-, and both the 10- and 15-min delay conditions.

\section{EXPERIMENT II ${ }^{1}$}

The first experiment showed that the effect of shock on immobility remained pronounced for a considerable period of time after the receipt of shock.
Previous research (Gallup et al., 1970b) has shown that strong shock potentiates tonic immobility more than weak shock. The second study examined the effect of shocks of constant intensity but different duration.

\section{Method}

The subjects were 45 Production Red chickens (Gallus gallus). The apparatus and procedure were identical to those of Experiment 1 , except that all subjects were tested immediately after shock termination. Subjects received a $3.5-\mathrm{mA}$ dc shock of $.25,1.0,2.0$. 5.0 , or 10.0 sec duration, depending upon treatment designation.

\section{Results}

A U-shaped function, relating the effect of different durations of dc shock, is illustrated in Figure 2. Brief shock appeared to potentiate immobility more than shocks of intermediate duration. The duration of immobility data were normalized via a $\log _{10}$ transformation and analyzed, using a one-way analysis of variance. The overall effect of shock duration was signiticant, $F(4,40)=4.71, p<.004$. A Duncan's multiple range test showed that the $2.0-\mathrm{sec}$ shock condition resulted in significantly $(p<.05)$ shorter durations of immobility compared to both the .25- and 10 -sec shock conditions. In addition, the 1.0 -sec shock condition resulted in signiticantly shorter immobility durations compared to the 10 -sec shock condition.

Analysis of the induction data failed to reveal a significant shock duration effect.

\section{EXPERIMENT III}

The effects of brief, as opposed to intermediate, dc shock durations in Experiment II fit in with the idea that the effectiveness of dc shock is based on the temporal spacing between onset and offset: with longer duration shock, the less the recruitment and the less aversive the shock. Since a pulsating de shock provides for a series of shock onsets and offsets, an attempt was made to contrive a pulsating de shock source to compare with continuous de shock at an intermediate shock duration. Steps were also taken to

Table 1

Means and Standard Deviations of the Number of Inductions Needed to Elicit Immobility as a Function of Time Since Shock (Minutes)

\begin{tabular}{|c|c|c|}
\hline \multirow{2}{*}{$\begin{array}{c}\text { Time Since } \\
\text { Shock }\end{array}$} & \multicolumn{2}{|c|}{ Number of Inductions } \\
\hline & Mean & $\mathrm{SD}$ \\
\hline .0 & 1.20 & .63 \\
\hline 2.5 & 1.70 & 1.25 \\
\hline 5.0 & 2.20 & 1.48 \\
\hline 10.0 & 1.90 & 1.45 \\
\hline 15.0 & 1.90 & 1.37 \\
\hline 60.0 & 3.30 & 1.89 \\
\hline 240.0 & 4.40 & .97 \\
\hline
\end{tabular}


Wamine the effects of ac shock, since Muenzinger and Wale (1932) have shown that pulsating shock, whether de or normal cycling ac, tends to be more aversive than continuous shock.

\section{Method}

The subjects were 40 Production Red chickens (Gallus gallus). purchased at 2 days of age from a hatchery in lowa and maintained as in the previous two experiments.

A constant-current shock source with provisions for $60 \cdot \mathrm{Hz}$ ac, 120- $\mathrm{H} \%$ pulsating $\mathrm{dc}$, and continuous dc outputs was built to yecifications provided by Stewart and Campbell (1970).

At 10 days of age the birds were divided randomly into four syuads of 10 each. At 12 days of age, the chicks were given 3 days $^{2}$ of habituation training following the procedure used in Experimen I. On the day after the last habituation trial, the subject received a $2 \cdot \mathrm{sec}, 3.0 \mathrm{~m}$ A shock of the appropriate type (ac, pulating de, continuous $d c$, or no shock), depending upon random treatment designation. Following shock termination. the birds were immediately restrained for 15 sec.

\section{Results}

The effect of different types of electric shock on both duration of immobility and number of inductions is presented in Table 2. A $\log _{10}$ transformation was perforned on the raw scores. Analysis of variance showed shock type to be

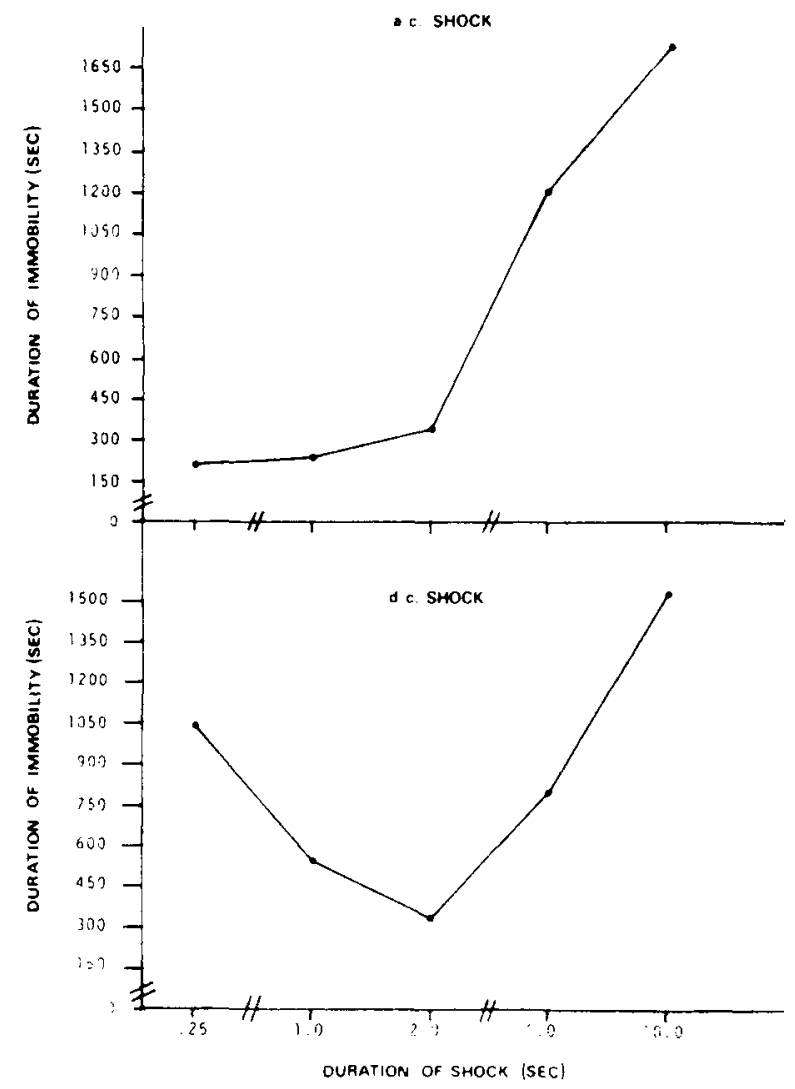

Figure 2. Duration of immobility as a function of the duration of both ac shock (Experiment IV) and continuous dc shock (Experiment II).
Table 2

Means and Standard Deviations of Immobility Duration (Seconds) and Number of Inductions Needed to Elicit Immobility as a Function of Different Types of Electric Shock

\begin{tabular}{lccccc} 
& \multicolumn{2}{c}{$\begin{array}{c}\text { Duration of } \\
\text { Immobility }\end{array}$} & & \multicolumn{2}{c}{$\begin{array}{c}\text { Number of } \\
\text { Inductions }\end{array}$} \\
\cline { 2 - 3 } \cline { 5 - 6 } Shock Type & Mean & SD & & Mean & SD \\
\hline Control & 56.61 & 86.41 & 1.70 & 1.49 \\
Continuous dc & 162.67 & 180.41 & 1.50 & 1.27 \\
Pulsating dc & 513.21 & 530.73 & 1.00 & .00 \\
ac & 329.21 & 172.01 & 1.40 & .52 \\
\hline
\end{tabular}

signiticant. $F(3,32)=6.18, p<.002$. A Duncan's multiple range test indicated that both ac shock and pulsating $\mathrm{dc}$ shock potentiated the duration of immobility significantly $(\mathrm{p}<.05)$ compared to the no-shock control group. There were no other group differences. Also, analysis of variance on the number of inductions needed to produce immobility showed no significant effects.

\section{EXPERIMENT IV}

This study was designed to investigate the effects of different durations of ac shock on immobility.

\section{Method}

Forty Production Red chickens (Gallus gallus) were purchased, maintained. and handied as in Experiment III. Except for the test condition, the procedure followed was identical to that in Experiment II

On the day atter the last habituation trial, the subjects received a $3.5 . m \mathrm{~A}$ ac shock of $.25,1.0,2.0,5.0$, or $10.0 \mathrm{sec}$ duration. depending upon random treatment designation. Eight birds were tested at each of the different shock durations.

\section{Results}

The effect of ac shock duration on immobility time is depicted in Figure 2; generally, birds receiving the same shock intensity for longer durations remained in mobile for longer periods of time. Analysis of variance computed on the transformed (log 10) duration data yielded a significant main effect. $F(4,30)=4.79 . p<.004$. Duncan's test showed that the .25-sec shock produced shorter durations of immobility compared to both the 5.0 - and $10.0-\mathrm{sec}$ conditions $(p)<.05)$. The 1.0 -sec shock condition produced signiticantly shorter reactions than the 10 -see condition, and the 5 - and 10 -sec shocks resulted in longer immobility periods than the 2.0 -sec condition.

Analysis of variance computed on the induction data showed no signiticant effects.

\section{DISCUSSION}

Fiperiment I failed to reveal any tendency for fear to incubate "ith time sinc" shock, as stggested by Denny and Ditchman (1962) it their explanation of the "Kamin effect." Rather. the effects of hack on tonic immobility remain promounced at least until 15 min 
after the receipt of shock, and only then become attenuated with longer delays.

The effect of shock duration on immobility appears to be a function of the type of shock used. A $\mathrm{U}$-shaped function relating durations of continuous de shock and duration of immobility was tound in Experiment II; Experiment IV showed that a more monotonic function holds for varying durations of ac shock. Since the aversiveness of a given intensity of de stimulation is primarily due to its onset and offset, the de duration data could be viewed as resulting from the delay of two transients: with longer delays (longer shock duration), there is less recruitment; consequently, the less aversive shock results in shorter immobility duration times. With 5 and $10-\mathrm{sec} d \mathrm{de}$ shock durations, the duration of immobility increased, suggesting that these shock durations were more aversive than the 2 -sec de shock. This could be due to a breakdown in subject resistance at such long durations, resulting in increasingly intense stimulation. Consistent with this interpretation, the more linear-like ac function is probably due to the fact that for a given current intensity ac shock provides for many repetitive shock onsets and oftsets.

Although the differences in Experiment 11 between the effects of ac and pulsating dc shock compared to continuous dc shock were not statistically signiticant, the data lend support to the notion that. for a given shock intensity, pulsating shock (dc or normal cycling ac) tends to be more aversive than continuous shock.

laken together, the results of all four experiments show that different dimensions of electric shock can have substantial effects on tonic immobility, and in the light of previous research (e.g., Gallup et al. $1970 \mathrm{a}, \mathrm{b}$ ) implicate immobility duration as a sensitive index of shock. However, number of inductions proved to be less reliably related to different parameters of shock.

\section{REFERENCES}

Denny, M. R., \& Ditchman, R. E. The locus of maximal "Kamin effect" in rats. Journal of Comparative and Physiological Psychology, 1962, 55, 1069-1070.

Gallup, G. G., JR. Tonic immobility in chickens: Is a stimulus that signals shock more aversive than the receipt of shock? Animal Learning \& Behavior, 1973, 1, 228-232.

Gallup, G. G., Jr. Animal hypnosis: Factual status of a tictional concept. Psychological Bulletin, 1974, 81, 836-853.

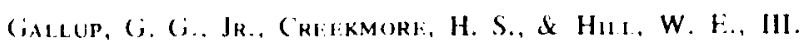
shock-cohanced inmobility reations in chickens: Support for the teat hypolnesis. Psyeholengical Revat. 1970, 20, $243 \cdot 245$, (it)

Gallup, G. G.. Jr.. Nash, R. F., Potter, R. J., \& Donegan, N. H. Effect of varying conditions of fear on immobility reactions in domestic chickens (Gallus gallus). Journal of Comparative and Physiological Psychology, 1970. 73, 442-445, (b)

Maser, J. D., a Gallup. G. G., Jr. Tonic immobility in shickens: (atalepsy potentiation by uncontrollable slock and alleviations by inipranine. Psychosomatic Medicine, 1974, 36. 194. 205

Mastar, J. D.. Gallup, G. G.. JR.. \& Barnhill, R. Conditioned inhibition and tonic immobility: Stimulus control of an innate fear response. Journal of Comparative and Physiological Prichology, 1974, 83, 128-1.33.

MuenzingFr. K. F., \& WALZ, F. C. An analysis of the scectrical stimulus producing shock. Journal of Comparative Psichology, 1932, 13, 157-171.

Sirwart, R. A., \& Camphell, S. L. A constant-current shock source for providing direct or alternating current output. Behavior Research Metheds \& Instrumentation. 1970, 2. 224.226 .

\section{NOTES}

1. This experinent has been included to provide intomation for rescarchers in this area who use continuous de shock. Since de stimulation is mainly effective at onset and oftset, with longer shock durations subjects might receive unpredictable stimulation due to either porer electrode comtact or to changes in subject resistance ats a result of moving about. Howerer, such unpredictable stimulation in the present study was reduced, since while being shocked the birds nere restricted from moring alout, and electrode contact was maximied by wrapping the legs with bare shock leads.

2. Unpublished data from unr laboratory has shown that 3 habituation training daly are an effective as 4 .

(Received for publication January 27, 1975: revision received April 17, 1975.) 